\title{
CFD simulation and investigation of a new radial flow field structure on the PEMFC circular bipolar plate
}

\author{
Qizhen Xie ${ }^{1}$, Yutao Lian ${ }^{2}$, Minggang Zheng ${ }^{1 *}$ \\ ${ }^{1}$ School of Mechanical and Electronic Engineering, Shandong Jianzhu University, Jinan 250101, \\ Shandong, PR China \\ ${ }^{2}$ School of Automotive Studies, Tongji University, 4800 Caoan Road, Shanghai, 201804, China \\ *E-mail: why1318@sdjzu.edu.cn
}

Received: 30 June 2021 / Accepted: 18 August 2021 / Published: 10 September 2021

\begin{abstract}
Proton exchange membrane fuel cells (PEMFCs) have received considerable attention in recent years as an efficient method of utilizing hydrogen energy. In PEMFCs, the bipolar plate is an important component, and flow channel design plays an important role in reaction gas distribution and product removal. Based on the circular bipolar plate structure, a new radial flow channel design scheme is proposed in this paper. This scheme adopts a central inlet method, where the gas enters from the center of the flow field and then diffuses around, and the adjacent flow channels transfer the reaction gas and products through the holes located in the middle of the ribs. The number of rib floors and the number and arrangement of holes on each rib floor are selected as the key variables of this structure, and PEMFC monomer models with differences in the above variables are established and then simulated by the CFD method. After a comparative analysis of the difference in oxygen distribution, water removal and cell output performance of each scheme, a comprehensive optimal design for this radial flow channel structure is finally proposed.
\end{abstract}

Keywords: Proton exchange membrane fuel cell; circular bipolar plate; radial flow channel; CFD simulation

\section{FULL TEXT}

(C) 2021 The Authors. Published by ESG (www.electrochemsci.org). This article is an open access article distributed under the terms and conditions of the Creative Commons Attribution license (http://creativecommons.org/licenses/by/4.0/). 